\title{
EFFECTS OF NICOTINE ON THE UNITARY ACTIVITY OF MEDULLARY RESPIRATORY NEURONES IN THE CAT
}

\author{
TAKEHIKO HUKUHARA, HIROSHI KOJIMA, HAJIME TAMAKI, \\ YOSHIAKI SAJI, NORIYUKI KUMADAKI AND FUMINORI SAKAI \\ Department of Pharmacology, Faculty of Medicine, University of Tokyo, Bunkyo-ku, Tokyo
}

Received for publication November 18, 1965

The alteration of the respiratory movements after the intravenous injection of nicotine (25-200 $\mu \mathrm{g} / \mathrm{kg})$ wcre classified usually in to following three phases; initial brief depression, the excitation, and the secondary depression phase.

This experiment was undertaken to get more exact information concerning those changes by means of recording the respiratory unit discharge in the medulla. Cats were immobilized under artificial respiration or anesthetized with pentobarbital. In the initial phase inspiratory as well as expiratory unit activities were depressed (Fig. 1-2) and we continued to observe this phase after the following procedures :

a) the severance of the bilateral sinus nerves, b) brainstem transection at the level of the pontomedullary junction, c) spinal cord transection between $\mathrm{C}_{6}$ and $\mathrm{C}_{7}$.

Only bilateral vagotomy could abolish this phase completely.

In the second phase, the inspiratory as well as expiratory unit activities enhanced (Fig. 1-3) and these changes were still observed in the isolated brainstem.

These results indicate that the second phase excitation may be caused by the direct action of nicotine on the central respiratory mechanism.

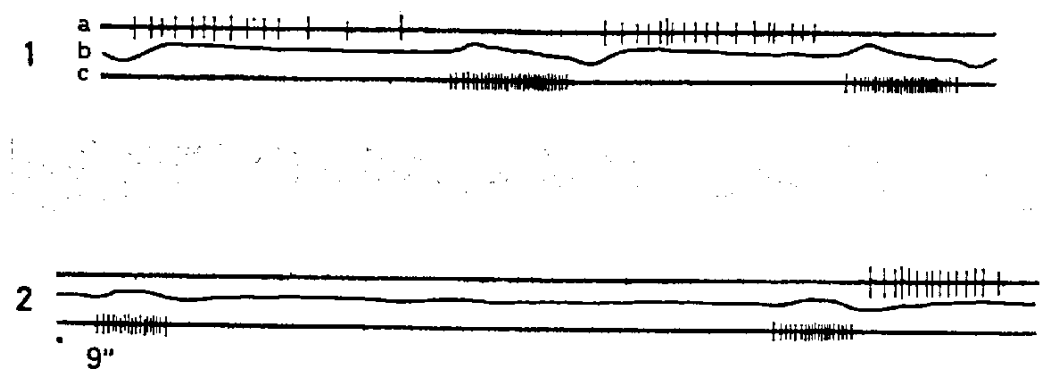

3

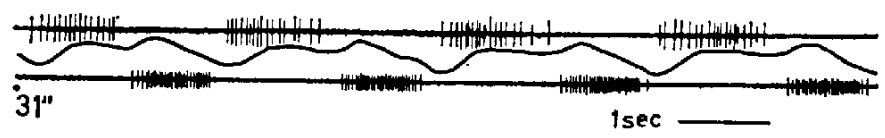

FIG. 1. Changes of respiratory unit discharges in both phases of initial depression and excitation by intravenous injection of $10 \mu \mathrm{g} / \mathrm{kg}$ nicotine in an anesthetized cat. 1 : control period, $2: 9$ seconds after injection, note disappearance of discharge of both units, $3: 31$ scconds after injection. a, expiratory unit discharge, b, pneumotachogram, inspiration upperward, $c$, inspiratory unit discharge.

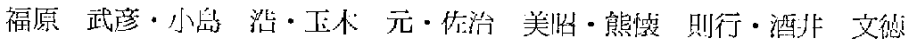


In the third phase, secondary depression, the unit activities of inspiratory and expiratory neurones were both depressed, however, these changes were not observed after the brainstem transection at the level of the ponto-medullary junction.

\section{SPECIES DIFFERENCE IN THE INHIBITION OF DRUG METABOLISM IN LIVER MICROSOMES BY SKF 525A \\ RYUIGHI KATO AND MIGHIKO TAKAYANAGI \\ Department of Hharmacology \& Taxicology, National Institute of Hygenic Sciences, Setagaya-ku, Tokyo}

Rcceived for publication November 19, 1965

SKF 525A ( $\beta$-diethylaminoetyldiphenyl-propylacetate $\mathrm{HCl}$ ) is a well known potent inhibitor of the drug metabolism in liver microsomes, the mechanism of inhibition is not yet elucidated (1).

Netter (1) has reported that SKF 525A noncompetitively inhibits O-demethylation of o-nitroanisole by rat liver microsomes. On the other hand, McMahon (2) has reported that N-demethylation of butynamine by rat liver microsomes is competitively inhibited by SKF 525A.

These studies were done with only rat liver microsomes, thus the purpose of present studics is to investigate these problems by use of different species of animals and different kinds of drugs.

The methods for the determination of drug metabolisms are almost same as reported in the previous paper (3).

As shown in Fig. 1-A and -B, it was demonstrated that SKF 525A competitively inhibits hydroxylation of hexobarbital, N-demethylation of aminopyrine and butynamine and O-demethylation of p-nitroanisole by rat and mouse liver microsomcs, however it inhibits non-competitively these processes

\section{Inhibition of hexobarbital metabolism by SKF525k in pats}

(A)

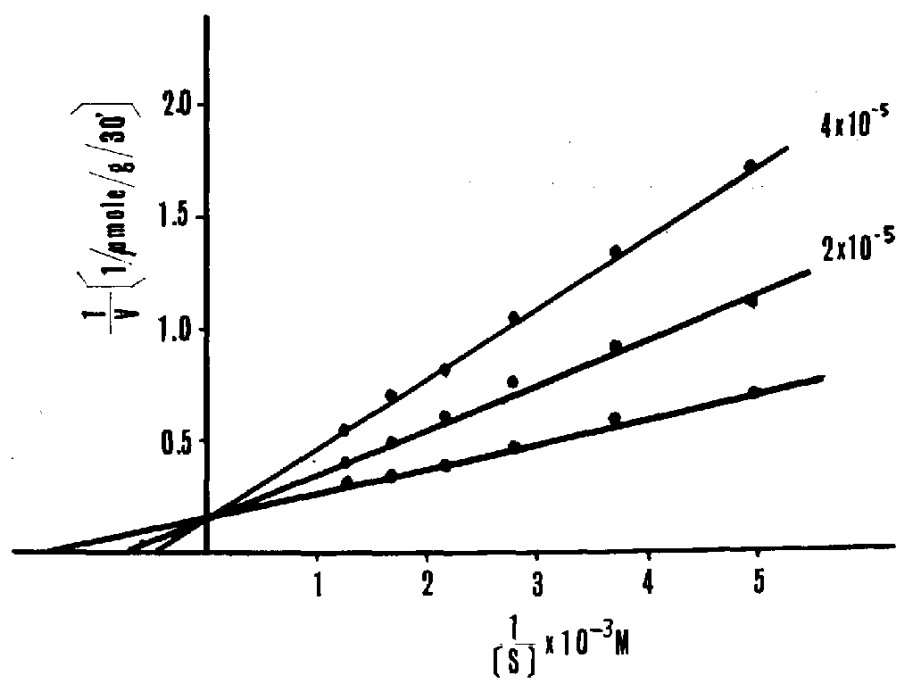

